\title{
A IRMANDADE DO ROSÁRIO EM CURITIBA - A OBLITERAÇÃO DOS NEGROS NA HISTÓRIA DA CIDADE
}

\author{
Pesquisa coletiva PET História UFPR ${ }^{1}$ \\ Douglas Figueira Scirea \\ Luccas Abraão de Paiva Vidal \\ Maurício Mihockiy Fernandez Martinez
}

\section{Introdução}

Anualmente, como parte das atividades do grupo PET-História, é realizada uma pesquisa coletiva. No ano de 2015, o tema escolhido foram as Irmandades Negras, com ênfase para a Irmandade do Rosário de Curitiba. Com relação a Irmandade de Curitiba, há pouca publicação e divulgação para uma instituição tão importante para o século XIX. Com nossos estudos, foi possível afirmar que as irmandades negras emergiram

“entre os séculos XVII ao XIX no Brasil, e foram respon-
sáveis pelas devoções católicas e pela promoção das pro-
cissões e festas, marcada pela grandiosidade das manifesta-

\footnotetext{
${ }^{1}$ Alunos integrantes do PET no decorrer da pesquisa: Aguinaldo Henrique Garcia de Gouveia, Bruna Trautwein Barbosa, Camila Quadros, Carolina Marchesin Moisés, Douglas Figueira Scirea, Lauriane dos Santos Rosa, Lucas Engel Sacht, Luccas Abraão de Paiva Vidal, Maria Victoria Ribeiro Ruy, Mariana Fujikawa, Mariana Mehl Gralak, Maurício Mihockiy Fernandez Martinez, Mayume Christine Minatogawa, Michel Ehrlich, Shirlei Batista dos Santos, Suellen Carolyne Precinotto, Thaís Cattani Perroni. Tutor: Prof. ${ }^{a} \operatorname{Dr}^{a}$ Renata Senna Garraffoni. Uma versão resumida desse texto também foi apresentada no $15^{\circ}$ ENAF da UFPR, em outubro de 2016.
} 
ções exteriores da fé e também marcada pelas questões políticas que envolviam as irmandades, o Estado e o poder eclesiástico" (SOUSA JÚNIOR, 2009).

Fica claro que as irmandades, mais do que instrumentos religiosos, eram um instrumento de socialização entre negros. A primeira regra para ser aceito no Brasil nessa época era ser Cristão - algo que conflui com os compromissos dessas instituições, que possuem como regra, o confrade seguir e professar a fé católica. Para Carlos Lima (2002), as visões do século XVIII sobre as confrarias negras, mostram que as irmandades teriam uma especificidade, a de ser algo "inocente", uma singela expressão de aflição, ou seja, o universalismo católico estaria seguro. Sendo assim, “as irmandades eram regidas pelos compromissos que deveriam ser aprovados pela Igreja Católica, Presidente de Província e pela autoridade monárquica" (SOUSA JÚNIOR). As Irmandades, no geral, tinham um caráter de agregação da população negra, com uma socialização interna e com uma criação de hierarquias no seio dessas instituições. A de Curitiba não fugiu à regra, e serviu, no século XIX, como modo de controle social entre senhor e escravo, com o universalismo católico sendo preservado.

\section{A Irmandade em Curitiba}

As leituras iniciais feitas pelos integrantes do PET levaram do geral ao específico. A Irmandade de Curitiba foi então colocada como foco de estudo. Com as leituras, notou-se um aumento da população de Curitiba no decorrer do século XVIII. O fator responsável por isso foi a pe- 
cuária, que demandou um aumento do número de escravos, cristalizando essa prática na região (WEBER, 2005), contradizendo a tendência de embranquecer a história do Sul do país. Ele descreve a população, afirmando que a maioria dos escravos era crioula. As irmandades tentavam se inserir na sociedade através da religião. Lima (2002) problematiza essa questão, mostrando que há várias interpretações que diziam que o catolicismo dessas irmandades seria um catolicismo híbrido, misturado com as crenças africanas, havendo um sincretismo religioso - para esse autor, esse sincretismo é difícil. Para ele, "as irmandades do Rosário eram frequentemente estabelecidas mediante algum tipo de afirmação étnica a princípio não-cristã, mas na verdade apontando para uma virtualidade de europeização" (LIMA, 2002). Ou seja, o princípio não cristão citado seria o ponto inicial de uma evangelização católica, e não algo a ser destruído. Outra ideia rebatida por Lima é de que essas irmandades seriam apenas fachadas. Os gastos e as festas realizadas pelos confrades eram todas católicas e voltadas à religião católica -, é difícil enxergar a Irmandade como fachada - mas, mesmo assim, não deixa de ser um modo de resistência, quando cria uma socialização negra que visa melhorias de condições.

É muito importante ressaltar que, contrário ao que pensávamos no início da pesquisa, essas confrarias não buscavam a abolição. Elas eram corporações, que estavam aptas a destacar-se da hierarquia e ser realocada nela. Ou seja, uma abertura para a mudança, através de ações e de interações com as posições de prestígio. Eram, portanto, um meio de inserção social negra. Por mais que essa Irmandade se destacasse, não 
exprimia posições sociais. É por isso que ela tem um lugar fundamental na ordem escravista. Muitas vezes, senhores inseriam seus escravos nessa corporação, para assim o cativo criar vínculos, desmotivando fugas e rebeliões. A doação de terras foi também uma tática usada pelos senhores, criando uma ação que Lima (2002) chama de "consentimento senhorial". Era uma negociação entre desiguais, que permitia brechas para a resistência dos cativos, de diversas maneiras. Em Curitiba, a comunidade escrava não se formou em confronto com o patriarcalismo senhorial, mas sim em articulação com ele. Um fator que comprova a hierarquia nessas confrarias eram os cargos - eram fortemente estratificados.Lima (2002) afirma que o modelo de compreensão das irmandades é o de "inclusão subordinada", ou seja, dava uma "cidadania" a pessoas de baixa representatividade ao invés de excluí-las da sociedade, sem no entanto, elevar o prestígio pessoal do confrade.

\section{As funções e objetivos da Irmandade em Curitiba}

Como já dito, as irmandades foram responsáveis pela devoção católica nas comunidades. As principais funções que essas irmandades possuíam se referiam as festividades e aos enterros dos irmãos, além de possuírem funções sociais muito bem esclarecidas, como "ajuda aos necessitados, assistência aos doentes, visita aos prisioneiros, concessão de dotes, proteção contra os maus tratos de seus senhores e ajuda para comprar ou negociar a carta de alforria" (SOUSA JÚNIOR, 2009).Essas festividades causavam rivalidades entre irmandades, sendo o momento pelo qual a irmandade era reconhecida na sociedade, e por isso, quanto 
maior e mais luxuosa fosse a festividade, mais a irmandade seria inserida na comunidade.Porém, o que mais fica marcado nas irmandades era a garantia de um enterro aos confrades. Com os estudos de Lima (2002) sobre os óbitos da Irmandade na cidade de Curitiba, chegamos à conclusão que a rotatividade de escravos nesse período (século XIX) era muito grande. Isso contrasta com a recente invisibilidade presente hoje em dia, no contexto da história dos negros não só na cidade de Curitiba, mas também em todo o Sul do Brasil. Na irmandade negra curitibana aqueles que não fossem ao enterro seriam expulsos da corporação, salvo com justificativa coerente. O luxo e a posição social do irmão morto eram refletidos no enterro. Quanto mais pomposo, mais importância o confrade tinha em vida, em relação a irmandade. Os dados nos revelaram mais detalhes sobre a irmandade de Curitiba. Ela pode ser definida como constituída por um grupo formado prioritariamente por escravos homens adultos, cercados por mulheres e idosos. As etnias eram fatores de exclusão. A prática confrarial se ligava a etnicidade como negociação e as identificações étnicas provavelmente serviram como mecanismos de exclusão. Por conta disso, pode-se afirmar que essas confrarias negras tinham mais tendência a se desestruturarem do que a crescerem.

\section{O compromisso da Irmandade de Curitiba}

A fonte por nós utilizada nesse trabalho são os compromissos das Irmandades do Rosário e de São Benedito da cidade de Curitiba, do ano de 1851, sendo o Paraná então, ainda uma província de São Paulo. Nesse compromisso, é possível identificar toda uma hierarquia interna dos 
cargos da Irmandade, e como eram definidos os cargos dos confrades. A morte e as festas religiosas constituem as duas principais presenças nesses compromissos, com a festa sendo o acontecimento principal da confraria no dia 26 de Dezembro, enquanto a morte era tratada com muita seriedade.

\section{A Obliteração}

Com a pesquisa sendo realizada, outro problema surgiu: por que, quando tão notadamente houve uma Igreja dos Pretos, os negros são tão obliterados da história de Curitiba e do Paraná? Por que se presume que não houve escravidão nesse Estado? Tentamos responder essas perguntas, baseado em autores como Hilton Costa (2011), utilizando como apoio nos dados demográficos a tese de mestrado de Elvira Mari Kubo (1974). É necessário entender que o fim da escravidão, no Brasil, coincidiu com a vinda dos imigrantes europeus. Os discursos desse tempo, como os de Nina Rodrigues praticamente descartam a presença negra em todo o Brasil Meridional. Rodrigues mostra um Brasil altamente europeizado, devido a vinda dos imigrantes, negando uma cultura negra no Sul do país. Usando Joinville, em Santa Catarina, e Caxias do Sul, Costa (2011) apresenta fatos importantes para a compreensão da europeização no Sul: é dado que as cidades só começaram a ser habitadas após a vinda dos imigrantes, exclusivamente alemães e italianos, excluindo até mesmo a presença de lusitanos. Fica claro que esse discurso faz "que o período imediatamente anterior a chegada dessas populações é obliterado e/ou tem sua importância bastante reduzida, quase negada" 
(COSTA, 2011). Com Curitiba a situação muda. Como a cidade foi fundada em 1693, a obliteração das sociedades anteriores fica mais difícil - porém, na própria apresentação da cidade, há um claro favorecimento dos europeus, quando dizem que os imigrantes deram uma nova conotação a cidade no início do século XX. Portanto, essa imigração europeia dará início a uma ideia de civilização na região sul, com esse discurso se tornando hegemônico e apagando a história negra da região. Já no fim do século XIX, ou seja, no fim da escravidão, as elites começaram a aderir as teorias do racismo científico. Quando a hierarquia social pautada na escravidão cai, a elite precisa de teorias que rebaixem as outras raças, para manterem seus benefícios. Hilton Costa (2011), analisando Rodrigues, mostra que ele foi adepto do racismo científico, e que seu discurso coloca o branco europeu como a raça hegemônica, querendo então a europeização da população. Por ser branca a raça hegemônica, os problemas sociais do Brasil estariam ligados com a má "qualidade" das pessoas aqui viventes, sendo necessário então, brancos virem para cá. Isso já mostra que não somente negros, mas índios, são a causa dos problemas sociais nessa interpretação, sendo então, obliterados nesses discursos de finais do século XIX. À população negra é dada nenhuma atenção, e quando dada, somente serve para mostrar a inferioridade da raça. O discurso obliterador então ganhou força e se estabeleceu, sendo muito forte até os dias de hoje, com a imagem e a memória dos negros sendo diminuída e apagada constantemente em prol de uma cultura branca e europeia. 


\section{A Igreja do Rosário: O objeto arquitetônico numa relação História \& Cidade}

Devido a dificuldade encontrada pelo desaparecimento da documentação referente a Igreja do Rosário no "Arquivo Público do Estado do Paraná", tomamos a liberdade de procurar outras formas de problematizar historicamente a questão da Igreja do Rosário. Deste modo, optamos por analisar a arquitetura do edifício, numa relação Cidade e História. Para tal nos baseamos em dois pensadores: o arquiteto Giulio Argan (1984), e o planejador urbano Kevin Lynch (1996). O principal ponto trazido por estes autores é a questão da capitalidade, ou seja, o espaço que a Igreja ocupa, e seu contraste com as edificações ao seu entorno. Este termo diz respeito a qual posição o edifício ocupa em uma cidade, como ele se relaciona com as pessoas que transitam ao seu redor, quais outros prédios foram sendo construídos ao seu entorno, se algum dos "organismos" da cidade tem preocupação com a posição do edifício. Com o seu histórico percebemos que ao ser primeiramente edificada, por volta de 1737 , não tinha tamanha visibilidade espacial. Mesmo posicionada no topo de uma colina, sua construção original não possuía tanto destaque como as torres das outras edificações, além de se encontrar na "borda" do centro. Quando inaugurada chamava-se "Igreja Nossa Senhora do Rosário dos Homens Pretos de São Benedito”, construída e frequentada pelos escravos até o período da abolição, quando passou a ser conhecida como "Igreja dos Mortos" pelo seu cemitério e ritos funerários. Demolida em 1937 devido ao seu péssimo estado de conservação ereconstruída em 1938 pelo arquiteto Eduardo Fernando 
Cadernos de Clio, Curitiba, v. 7, nº. 2, 2016

Chaves. Além de o processo ter sido lento e sem muita verba, o arquiteto falece em 1944, dois anos depois uma comissão é elencada para reconstrução em 1946. Mas somente em 1951 a Igreja iniciou suas atividades, sendo confiada aos padres jesuítas. É válido ressaltar que a reconstrução fez parte de uma série de reformas no centro histórico visando conservar as construções de época tipicamente paranaenses. Depois desta reconstrução ocorreram uma série de mudanças na estrutura da Igreja. Não se tem muita informação sobre a arquitetura da Igreja Antiga, salvo que pertencia ao Estilo Colonial, apenas com uma nave central, e uma rosácea e janelas laterais que a aproximam do estilo românico e colonial, sem a torre e as janelas de vitrais de agora.

Vide imagens:

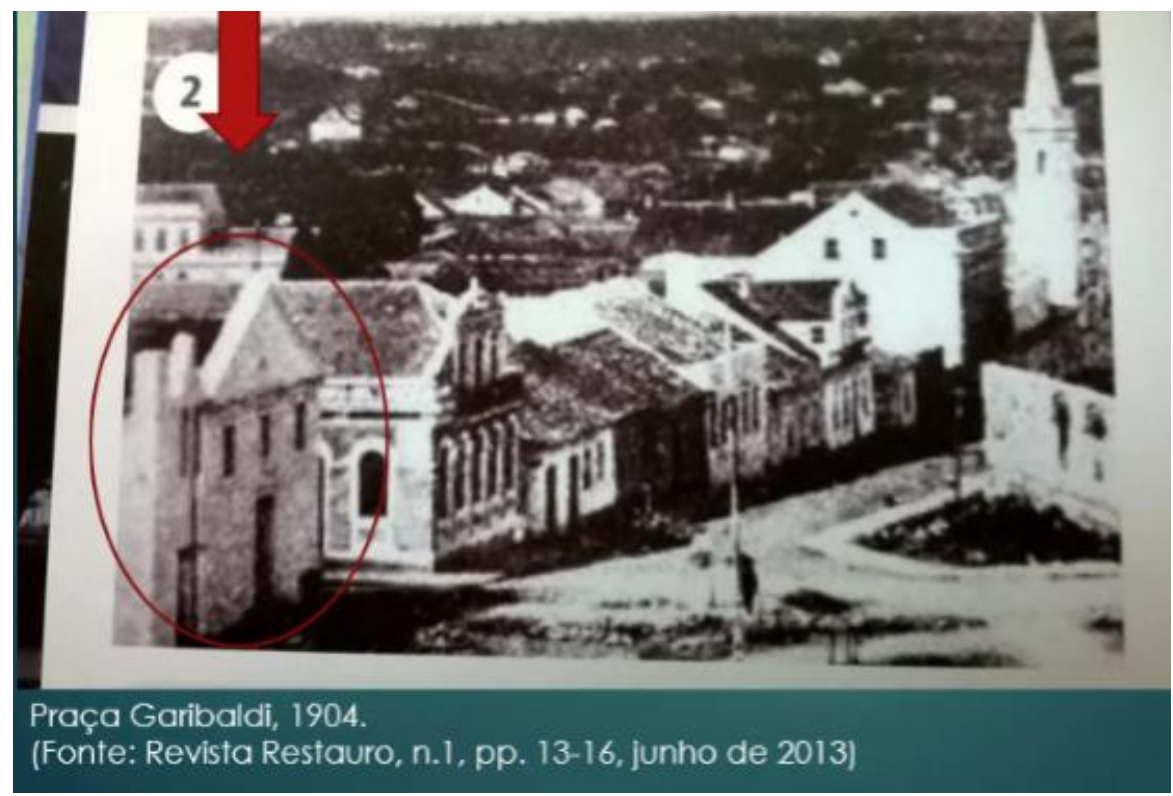


Cadernos de Clio, Curitiba, v. 7, nº 2, 2016

Vide imagem do projeto atual:

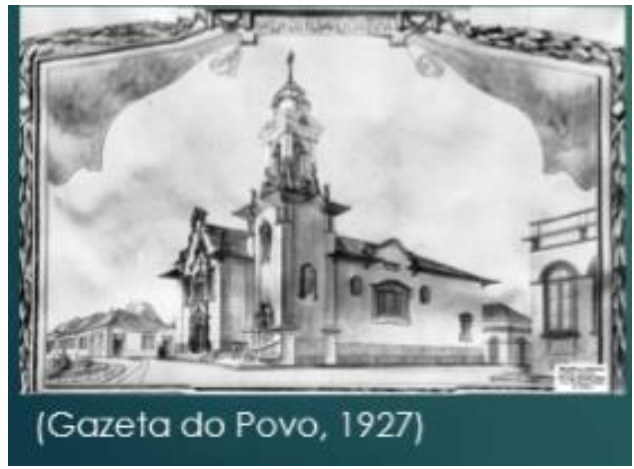

(Jornal Gazeta do Povo, 1927, acervo da Biblioteca Pública do

Paraná)

Após sua demolição, foi reconstruída seguindo um estilo barroco tardio, com a construção de uma torre, e orientada pelos elementos deste estilo arquitetônico, uso da pintura e escultura preenchendo os espaços vazios da construção de forma harmônica, utilizando internamente efeitos dramáticos de luz e sombra. Porém, ao analisar seus elementos, e olhando para seu entorno, observamos a dificuldade de enquadrar a Igreja em um estilo arquitetônico propriamente dito, tendo em sua atual estrutura alguns elementos do estilo Arquitetônico Eclético, definido por Pedone (2004) como sendo "(...) o procedimento que buscou inventar uma arquitetura adaptada aos novos tempos, por meio do uso de elementos e de sistemas escolhidos na história da arquitetura, com o objetivo de criar novas composições". Ao analisar mais a fundo esta reforma, nos atrelamos a uma notícia do Jornal Gazeta do Povo de 01 de outubro de 
1927, nela temos a divulgação do novo projeto da Igreja, desenhada e projetada por Eduardo Fernando Chaves. E, também uma entrevista com o Monsenhor Celso (1849-1930), publicada no Jornal Gazeta do Povo em 25 de agosto de 1928. A partir disso, pudemos notar algumas preocupações e exigências do Monsenhor Celso, em sua maioria, preferindo reconstruir a igreja exatamente e fielmente como ela era antes da reforma:

“(...) construida pela subscripção do povo curitybano e sob os auspicios do venerado prelado paranaense, Mons. Celso (...) O projeto formossisimo, que reconstroe completamente e moderniza a velha Egreja, não lhe tira, porém, as actuaes linhas architectonicas, que já são tradiccionaes na vida da cidade. O projeto que será exposto na vitrine de "O Louvre", é do abalizado artista paranaense (...) architectodr. Eduardo Fernando Chaves." (01/10/1927, Gazeta do Povo).

Primeiro, existia uma vontade do "povo curitibano" e um contato direto do Monsenhor Celso na feitura do projeto. Segundo, o projeto reconstrói e moderniza, porém não lhe tira as linhas tradicionais da vida na cidade. Na verdade este é um equívoco, comparando as linhas da Igreja atualmente. Com seu falecimento um pouco antes do inicio das obras, o projeto foi alterado por Chaves buscando "modernizar" o edificio e coloca-lo em harmonia com as demais edificações vizinhas. No caso, fazendo uma análise da presença da Igreja ao longo do século XX aos dias de hoje, e nos atentando a questão da capitalidade mencionada por Lynch e Argan, percebemos que ela se encontra em um espaço turístico da cidade. Tanto as vias, ruas, e o próprio bairro apontam para isso. 
Na Rua Doutor Claudino dos Santos não é comum à passagem de carros, sendo fechada e ladrilhada para uso exclusivo de pedestres, cortada pela Rua do Rosário e a Duque de Caxias. Ao longo de sua extensão, no entorno da Igreja, nota-se a presença de muitos bares, casas de artesanato, outras igrejas, praças, construções históricas, restaurantes, e nos domingos as ruas são interditadas pela tradicional feira do Largo da Ordem.

Atualmente, a Igreja é relativamente alta e se destaca dos demais prédios da região, por sua torre e nave altas, além de ocupar boa parte da quadra e estar em frente a uma praça - sendo possível observa-la com destaque na Rua XV de Novembro. Embora no Largo da Ordem ocupe certo papel de destaque, acaba ofuscada pela Catedral de Curitiba, que fica na quadra de baixo, na Praça Tiradentes. Ela está encaixada no circuito turístico como a Igreja dos Negros, última parada da linha turismo, no setor histórico da cidade. É um patrimônio de conservação como a maioria dos prédios por perto. O seu papel como templo, além de ter uma história que data ao século XVIII, ajudam a torná-la um importante elemento da região, carregando uma forte memória da cidade. Existem ainda festejos e celebrações na própria Igreja, porém, ao observarmos o espaço em torno, vemos como a cidade cresceu. Os prédios altos, as ruas estreitas e os outros pontos turísticos no entorno ofuscam bastante a Igreja do Rosário. É difícil observa-la de longe, mesmo estando em um local alto, e quando comparada a arquitetura moderna ao seu entorno, nota-se que é um edifício um pouco deslocado. 


\section{Conclusão}

Por fim, a partir de todas as considerações sobre a Irmandade do Rosário, podemos afirmar a importância desta ordem religiosa devido a tantos reflexos obtidos pelas exposições de toda estrutura dessa irmandade em uma cidade que na época teria algo muito inferior a cinquenta mil habitantes, sendo que pelo menos $10 \%$ da população era notadamente negra e escrava. Pelos registros de óbito utilizados na pesquisa de Carlos Alberto Lima (2002), e pelos estudos de Elvira Mari Kubo (1974), notamos o aumento do número de fiéis frequentadores da Igreja, o que significou um aumento do número de escravos ou um aumento em sua rotação. As instituições em si poderiam, em nossa visão, ser uma resistência ao sistema escravista. A linha entre a reprodução de um sistema e de um mecanismo de luta e resistência é muito tênue - não se sabe em que momentos as hierarquias eram usadas para tentar a alforria de alguns irmãos, mais notadamente os de maior ordem de hierarquia, ou quando apenas negociavam com senhores em troca de uma inserção e a consequente volta de uma identidade, mesmo que coletiva e sem prestígio.

\section{REFÊRENCIAS}

ARGAN, G. História da Arte como História da Cidade. Martins Fontes, SP, 1984.

BURY, John. Arquitetura e arte no Brasil Colonial. Org. Myriam Andrade Ribeiro de Oliveira. 1a Edição. Brasília, DF: IPHAN/MONUMENTA, 2006. 
CARPINTÉRO, M. V. T; CERASOLI, J, F. “A Cidade como história”. In: periódico História: Questões \& Debates. NADALIN, Sérgio Odilon (Org.). Curitiba, PR: Editora UFPR, ano 26, n. 50, jan./jun. 2009.

COSTA, Hilton. Ilusão de ótica: presença negra e imigração para o sul do Brasil nas análises de Raymundo Nina Rodrigues e Sílvio Romero. In: V Encontro Escravidão e Liberdade no Brasil Meridional, 2011, Porto Alegre, 2011.

FEDALTO, Pedro. A arquidiocese de Curitiba na sua história. Curitiba, 1958.

KUBO, Elvira Mari. Aspectos Demográficos em Curitiba: 1801-1850. 1974. Dissertação (Mestrado) - Curso de História, Departamento de História, Universidade Federal do Paraná. Disponível em: <http://acervodigital.ufpr.br/bitstream/handle/1884/24630/D - KUBO, ELVIRA MARI.pdf?sequence=1>. Acesso em: 14 jun. 2016.

LIMA, Carlos A. M.; MOURA, Ana Maria da Silva. Devoção \& Incorporação. Igreja, escravos e índios na América Portuguesa. Curitiba: Editora Peregrina, 2002.

LYNCH, K. A imagem da cidade. Martins Fontes. São Paulo. 1996.

PEDONE, Jaqueline VielCaberlon. O Espírito Eclético na Arquitetura. Arqtexto, Rio Grande do Sul, Volume 6, pp. 126-137, 2a Semestre de 2004.

RIBEIRO, Fabia Barbosa. Caminho da Piedade, caminhos da devoção: as irmandades de pretos no vale do Paraíba Paulista. 2010. 272 f. Tese (Doutorado) - Curso de História, Universidade de São Paulo, São Paulo, 2010.

SOUSA JÚNIOR, Jose Pereira de. Irmandades religiosas: espaços de devoção e disputas políticas na Paraíba oitocentista. In: SIMPÓSIO NACIONAL DE HISTÓRIA, 25. 2009, Fortaleza. Anais do XXV Sim- 
Cadernos de Clio, Curitiba, v. 7, nº. 2, 2016

pósio Nacional de História - História e Ética. Fortaleza: ANPUH, 2009. CD-ROM.

WEBER, Silvio Adriano. Escravidão e Irmandade Negra Nos Campos de Curitiba (1797-1850). 2005.

Gazeta do Povo. Edições: 08/04/1950; 03/01/1991; 01/10/1927; 25/08/1928. Disponíveis na Biblioteca Pública do Paraná.

Recebido em: 23/01/2017 Aceito em: 25/01/2017 